\title{
Molecular alterations associated with liver metastases development in colorectal cancer patients
}

\section{SC Bruin ${ }^{1,10}$, Y He$^{2,10}$, I Mikolajewska-Hanclich², G-J Liefers ${ }^{3}$, C Klijn ${ }^{4,5}$, A Vincent ${ }^{6}$, VJ Verwaal', KA de Groot ${ }^{7}$, $H$ Morreau', M-LF van Velthuysen', RAEM Tollenaar' and $L J$ van ' $t$ Veer ${ }^{*}, 2$}

'Department of Surgery, Division of Experimental Therapy, The Netherlands Cancer Institute - Antoni van Leeuwenhoek Hospital, Plesmanlaan 12 I, 1066 CX Amsterdam, The Netherlands; ${ }^{2}$ Division of Experimental Therapy, The Netherlands Cancer Institute - Antoni van Leeuwenhoek Hospital, Plesmanlaan 121, 1066 CX Amsterdam, The Netherlands; ${ }^{3}$ Department of Surgery, Leiden University Medical Center, Albinusdreef 2, 2333 ZA Leiden, The Netherlands; ${ }^{4}$ Department of Molecular Biology, The Netherlands Cancer Institute - Antoni van Leeuwenhoek Hospital, Plesmanlaan I 2 I, 1066 CX Amsterdam, The Netherlands; ${ }^{5}$ Delft Bioinformatics Lab., Delft University of Technology, PO Box 503I, 2600 GA Delft, The Netherlands; ${ }^{6}$ Department of Biometrics, The Netherlands Cancer Institute - Antoni van Leeuwenhoek Hospital, Plesmanlaan 121, 1066 CX Amsterdam, The Netherlands; ${ }^{7}$ MRC-Holland, Willem Schoutenstraat 6, 1057 DN Amsterdam, The Netherlands; ${ }^{8}$ Department of Pathology, Leiden University Medical Center, Albinusdreef 2, 2333 ZA Leiden, The Netherlands; ${ }^{9}$ Department of Pathology, The Netherlands Cancer Institute - Antoni van Leeuwenhoek, Plesmanlaan 121, 1066 CX Amsterdam, The Netherlands

BACKGROUND: Understanding the molecular biology of colorectal cancer (CRC) provides opportunities for effective personalised patient management. We evaluated whether chromosomal aberrations, mutations in the $\mathrm{PI}(3) \mathrm{K}$ signalling pathway and the CpGisland methylator phenotype (CIMP) in primary colorectal tumours can predict liver metastases.

METHODS: Formalin-fixed paraffin-embedded material from primary colorectal tumours of three different groups were investigated: patients with $C R C$ without metastases $(M 0, n=39)$, patients who were treated with hyperthermal intraperitoneal chemotherapy for CRC metastases confined to the peritoneum (PM, $n=46$ ) and those who had isolated hepatic perfusion for CRC metastases confined to the liver ( $L M, n=48)$.

RESULTS: All samples were analysed for DNA copy number changes, PIK3CA, KRAS, BRAF mutations, CIMP and microsatellite instability. The primary CRCs of the LM group had significantly higher frequency of amplified chromosome $20 q(P=0.003)$, significantly fewer mutations in the $\mathrm{PI}(3) \mathrm{K}$ signalling pathway $(P=0.003)$ and fewer CIMP high tumours $(P=0.05)$. There was a strong inverse correlation between $20 \mathrm{q}$ and the $\mathrm{PI}(3) \mathrm{K}$ pathway mutations.

CONCLUSION: The development of CRC liver metastases is associated with amplification of chromosome $20 \mathrm{q}$ and not driven by mutations in the $\mathrm{PI}(3) \mathrm{K}$ signalling pathway.

British Journal of Cancer (201 I) I 05, 28I-287. doi:I0.1038/bjc.20II.184 www.bjcancer.com

Published online 14 June 201 I

(c) 20II Cancer Research UK

Keywords: colorectal cancer; liver metastases; chromosome 20q; PI(3)K signalling pathway; PIK3CA; KRAS

Colorectal cancer (CRC) is the second leading cause of cancer death in the Western world. The WHO estimates that 945000 new cases occur yearly, with 492000 deaths (Weitz et al, 2005). The overall 5 -year survival is $57 \%$, and up to $50 \%$ of patients will develop metastases. Distant metastases are responsible for the great majority of CRC deaths, mainly due to liver metastases (Welch and Donaldson, 1979; Galandiuk et al, 1992; Sadahiro et al, 2003). Of all patients who die of advanced CRC, $60-70 \%$ have liver metastases (Weiss et al, 1986). Even with the use of targeted drugs, the overall survival in patients with non-resectable CRC liver metastases is only 2 years, and late detection of liver metastases is still fatal. Hepatic resection is the only potentially curative treatment for a subset of patients with colorectal liver metastases. In these patients with resectable liver metastases, a 5-year survival of $30 \%$ can be achieved, and up to $20 \%$ of this population will still

\footnotetext{
*Correspondence: Dr LJ van 't Veer; E-mail: I.vt.veer@nki.nl

${ }^{10}$ These authors contributed equally to this work.

Received 20 January 201 I; revised 28 April 201 I; accepted 3 May 201 I; published online I4 June 20 | |
}

be alive after 10 years. The eligibility for hepatic surgery depends on whether all metastases are resectable and an adequate liver function can be maintained. There should be no extrahepatic disease, with the possible exception of few resectable lung metastases (Rees et al, 2008). Fong et al (1999) created a clinical risk score to identify patients who would most benefit from liver resection and showed that two of the five factors were determined by the number and size of the metastases in the liver. Therefore, early detection of liver metastases is of utmost priority and can result in more radical surgery and thus long-term survival (Rodriguez-Moranta et al, 2006).

The current tumour node metastases staging system of CRC has great clinical utility for prognosis and adjuvant treatment decision, but provides no information about a site-specific risk for liver metastases. A better understanding of the molecular biology of CRC progression has the potential to provide this information.

Colorectal cancer arises and processes through an adenomacarcinoma sequence. This adenoma-carcinoma sequence follows well-defined steps of histological stages, each characterised by distinct mutations in oncogenes and tumour suppressor genes (Fearon and Vogelstein, 1990; Lengauer et al, 1997). The majority 
(85\%) of CRC are chromosomal instable, characterised by allelic losses, chromosomal amplifications, translocations, as well as gene mutations (Lengauer et al, 1997; Thiagalingam et al, 2001; Jass et al, 2002; Jass, 2007).

One of the pathways often affected in CRC is the PI(3)K signalling pathway. This pathway has a central role in tumorigenesis by regulating cell growth, differentiation and apoptosis (Vivanco and Sawyers, 2002; Samuels et al, 2004; Shaw and Cantley, 2006). In this pathway, PIK3CA, KRAS and BRAF genes are frequently activated by mutations in various tumour types, including CRC (Samuels et al, 2004; Oikonomou and Pintzas, 2006; Cardoso et al, 2007; Kato et al, 2007) with frequencies of $10-30 \%$ (Samuels et al, 2004; Velho et al, 2005; Kato et al, 2007; Barault et al, 2008; Nosho et al, 2008; Ogino et al, 2009b), 30-40\% (Vogelstein et al, 1988; Andreyev et al, 1998; Cardoso et al, 2007) and 5-22\% (Yuen et al, 2002; Cardoso et al, 2007), respectively. Mutations in any one of these three genes will activate the PI(3)K signalling pathway and increases the transcription of different oncogenes, such as $C-M Y C, C R E B, N F-k B$ and others (Barault et al, 2008), resulting in unrestricted cell growth.

There is a potential role of this signalling pathway in predicting survival (Kato et al, 2007; Barault et al, 2008); however, little is known about the relation between mutations in primary colorectal tumours and the risk of developing liver metastases. Furthermore, in our recent work we showed that an amplification of chromosome $20 \mathrm{q}$ is strongly related with the development of liver metastases (Bruin et al, 2010).

Here, we evaluated whether chromosomal aberrations and/or mutations in the $\mathrm{PI}(3) \mathrm{K}$ signalling pathway and $\mathrm{CpG}$-island methylator phenotype (CIMP) in primary colorectal tumours can predict liver metastases. Improved understanding of the biological mechanisms underlying liver metastases may allow tailored follow-up and potentially adapted management in patients with early-stage CRC

\section{MATERIALS AND METHODS}

\section{Patients and tumour samples}

Formalin-fixed paraffin-embedded material (FFPE) from primary colorectal tumours of three different groups were investigated: patients with CRC who had not developed metastases, median follow-up 8 years (M0, $n=39$ ); patients who had been treated with hyperthermal intraperitoneal chemotherapy for synchronous or metachronous CRC metastases confined to the peritoneum (PM, $n=46$ ) (Verwaal et al, 2003, 2008); and patients who had been treated with isolated hepatic perfusion for CRC synchronous or metachronous metastases confined to the liver (LM, $n=48$ ) (van Iersel et al, 2008). These three specific groups were selected to identify specific markers for LM, which are not particular for other metastatic localisations such as PM, nor characteristic for CRC that do not metastasise. The LM and PM groups were carefully screened at the time of diagnosis to ensure they were free of other distant metastases (Marinelli et al, 1998; Verwaal et al, 2003). Clinical and pathological characteristics were retrieved from computerised medical registries and existing study databases (Marinelli et al, 1998; Verwaal et al, 2003; van Iersel et al, 2008).

We used anonymised tissue material from patients with consent following standard operational procedures in the respective hospitals, approved by the Institutional Review Board. Tissue handling was anonymised following the Declaration of Helsinki.

\section{DNA extraction and mutation analysis}

DNA isolation was performed as described earlier (Joosse et al, 2007). Briefly, genomic DNA was isolated by proteinase $\mathrm{K}$ digestion after deparaffination from $10 \times 10 \mu \mathrm{m}^{2}$ FFPE tissue sections containing at least $70 \%$ tumour cells from both the M0 and PM group. For the LM group, DNA was isolated from FFPE tissue block punches. These punches were taken out of the tissue blocks in the area with at least $60 \%$ tumour cells.

For the mutation analysis, exons 9 and 20 of PIK3CA, exon 1 of KRAS and exon 15 of BRAF were amplified by PCR and the presence of mutations was detected by direct sequencing using the BigDye Terminator Cycle Sequencing Kit (Applied Biosystems, Carlsbad, CA, USA). For all PCR products with sequence variants, both forward and reverse sequence reactions were repeated for confirmation. Primers used for the amplification and the PCR conditions are available upon request.

\section{Microsatellite instability}

Analysis of microsatellite instability (MSI) was performed by using PCR and subsequent fragment analysis on an automated capillary sequence machine (ABI, 3730). The following eight markers were evaluated, including two mononucleotide markers (BAT 25 and BAT 40) and six dinucleotide markers (D1S158, D2S123, D5S346, D9S63, D17S250, D18S58). A tumour was considered to be MSIhigh when three or more markers showed instability, MSI-low when one or two markers showed instability and MSI-stable when none of the eight markers showed instability (Kets et al, 2008).

\section{CIMP status}

CpG-island methylator phenotype status was analysed by using the methylation-specific multiplex ligation-dependent probe amplification (MS-MLPA) kit (MRC-Holland, Amsterdam, the Netherlands; see Nygren et al (2005)). This MS-MLPA kit can be used to detect aberrant methylation of eight CIMP-specific promoters for CRC (CACNA1G, CDKN2A (p16), CRABP1, IGF2, MLH1, NEUROG1, RUNX3 and SOCS1) (Weisenberger et al, 2006; Ogino et al, 2009a). CpG-island methylator phenotype analysis was performed according to the manufacturer's protocol (SALSA MLPA kit, ME042-A1 CIMP; MRC-Holland). CpG-island methylator phenotype-high was defined as 6-8 methylated markers using the eightmarker CIMP panel and CIMP-low as 0-5 methylated markers (Ogino et al, 2007, 2009a).

\section{Chromosomal aberrations}

DNA copy number changes were investigated using the $3.5 \mathrm{k}$ bacterial artificial chromosomes (BAC) array performing array comparative genomic hybridisation as described previously (Joosse et al, 2009; Bruin et al, 2010). The human $3600 \mathrm{BAC} /$ PAC genomic clone set, covering the full genome at $1 \mathrm{Mb}$ spacing used for the production of our arrays, was obtained from the Welcome Trust Sanger Institute (http://www.sanger.ac.uk/). Information on this clone set can be obtained at the $\mathrm{BAC} / \mathrm{PAC}$ Resources Center Website (http://www.bacpac.chori.org/). The whole library was spotted in triplicate on every slide. To prevent slide batch spotting bias, samples were hybridised in random order (http://www.microarrays.nki.nl/).

\section{Statistical analysis}

A propensity score using the baseline clinical data was calculated to compare the three patient groups (M0, PM, LM). The propensity score was taken as the probability of liver metastases given a patients' age, sex, T-stage, $\mathrm{N}$-stage and primary location in a multinomial logistic regression model (D’Agostino Jr, 1998; Gleisner et al, 2008).

Patients missing baseline clinical data were imputed using median values. The association between genetic data $(B R A F$, KRAS, PIK3CA mutations, $\mathrm{PI}(3) \mathrm{K}$ signalling pathway (mutation in at least one of the three genes) and CIMP) and the occurrence of liver metastases was determined and adjusted for quartiles of the 
propensity score using exact Cochran-Mantel-Haenszel tests. Fisher's exact and Kruskal - Wallis tests were used to determine the strength of associations between baseline clinical and pathological characteristics and the occurrence of liver metastases.

\section{0q gain status}

To determine whether a tumour had a gained $20 \mathrm{q}$ arm, we calculated average total copy numbers (TC) for $20 \mathrm{q}$ in each tumour using the average $\log 2$ (AL2) of the BAC clones mapped to $20 \mathrm{q}$ (equation (1)). We assumed $70 \%$ tumour tissue in each sample, making this a conservative estimate of copy number.

$$
\frac{\left(2^{\mathrm{AL} 2}\right)-1}{0.7} \times 2+2=\mathrm{TC}
$$

We labelled all tumours with a TC $20 \mathrm{q}$ of $>2.5$ as $20 \mathrm{q}$ amplified (Bruin et al, 2010).

\section{RESULTS}

\section{Patient characteristics}

Table 1 presents the clinical and pathological characteristics for each of the three patient groups. Some of the patient characteristics are different among groups owing to the selection criteria employed for each group. These differences, however, were accounted for by using a propensity score for the evaluation of LM predictive markers (see below). More right-sided tumours were included in the M0 group, whereas the PM and LM group consisted of more left-sided colon and rectum tumours and of younger patients. There were more T4 tumours in the PM group compared with the M0 and LM group. As expected, the M0 group showed less $\mathrm{N}+$ tumours. All patients in the M0, LM group and the metachrone patients in the PM group achieved an R0 resection for their primary tumour. The range of follow-up in the M0 group of patients still alive without recurrent disease was 4.6-16.7 years (median 8 years). Five patients in the M0 group died before 5 years follow-up without metastases. Range of time between primary diagnosis and diagnosis metastasis for metachrone LM and PM patients is $3.4-37.5$ and 5.5-94.0 months, respectively.

\section{Mutation analysis}

KRAS, PIK3CA and BRAF and PI(3)K signalling pathway mutations In the combined study population $(n=133), B R A F$ mutations were identified in 11 cases (8\%), KRAS in 42 cases $(32 \%)$ and PIK3CA in 21 cases (16\%) (Table 2).

No significant differences were observed for the propensity score adjusted differences of PIK3CA, KRAS and BRAF mutations

Table I Patient characteristics

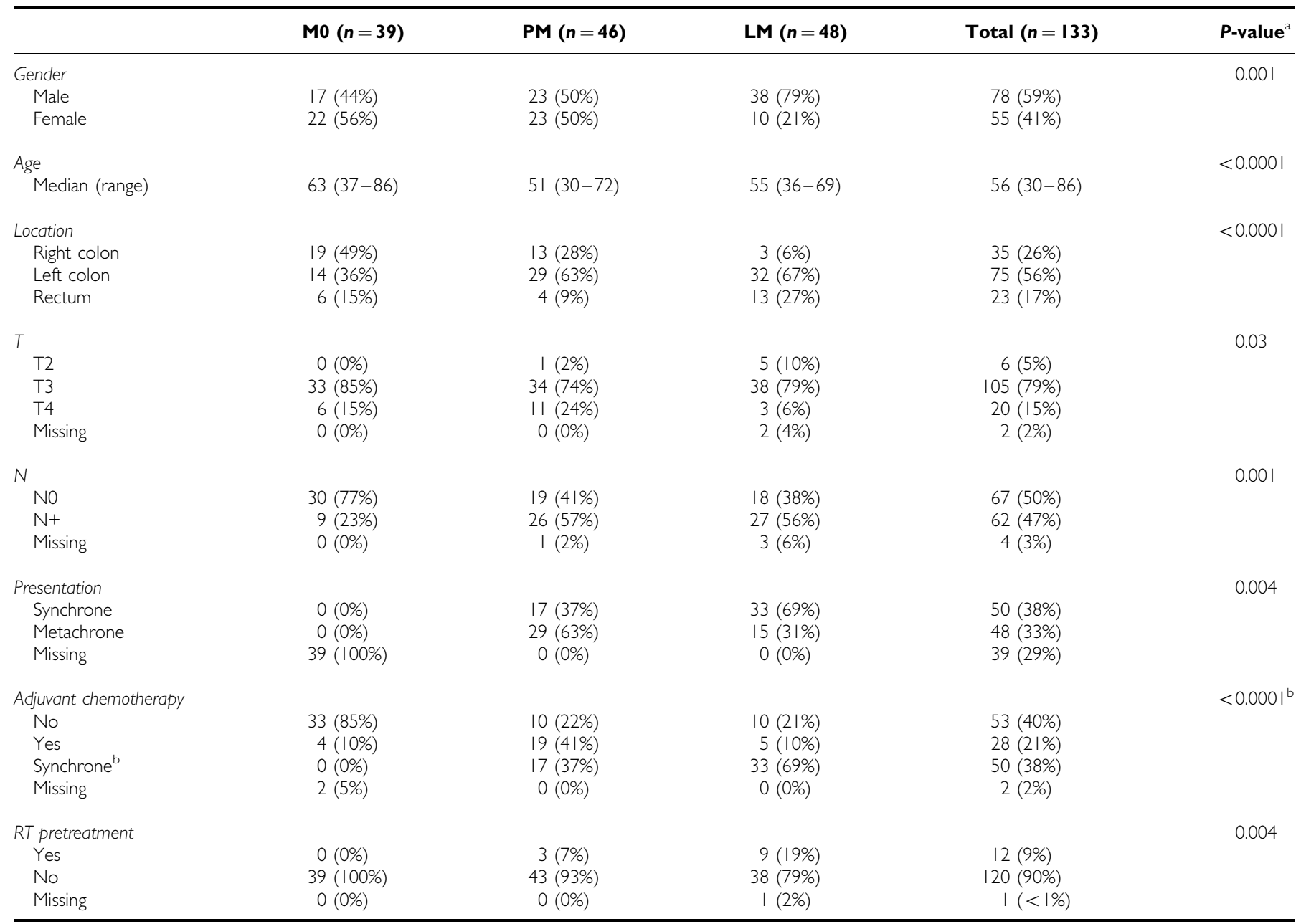

Abbreviations: $C R C=$ colorectal cancer; $H I P E C=$ hyperthermal intraperitoneal chemotherapy; $L M=$ liver metastasis; $P M=$ peritoneal metastasis. ${ }^{a} p$-value: association of clinicopathological characteristic with CRC subgroup. ${ }^{b}$ Patients who presented with synchronous metastasis in the LM and PM group could have received adjuvant chemotherapy as a part of their metastasis treatment (HIPEC or liver perfusion). Of note, this adjuvant treatment was given after metastasis treatment and therefore had no influence on the metastasis development. 
Table 2 Molecular analysis of primary CRC of MO, PM and LM patients

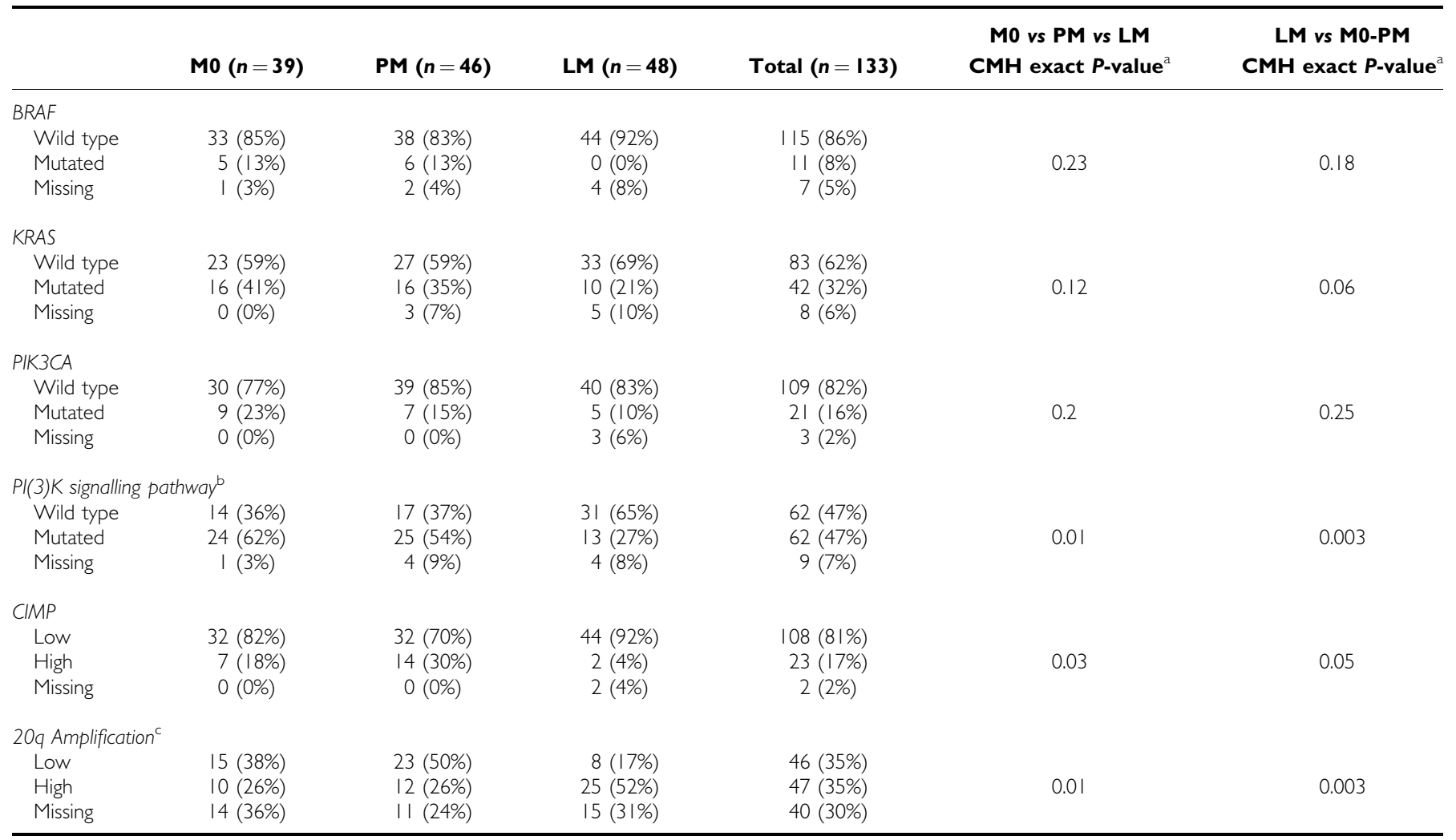

Abbreviations: $\mathrm{BRAF}=\mathrm{B}$-type Raf kinase; $\mathrm{CIMP}=\mathrm{CpG}$-island methylator phenotype; $\mathrm{CRC}=$ colorectal cancer; $\mathrm{LM}=$ liver metastasis; $\mathrm{PI}(3) \mathrm{K}=$ phosphoinositide 3-kinase; PIK3CA = phosphoinositide-3-kinase, catalytic, alpha polypeptide; $\mathrm{PM}=$ peritoneal metastasis. ${ }^{\mathrm{a}} \mathrm{CMH}=\mathrm{Cochran}-\mathrm{Mantel}-\mathrm{Haenszel}$ tests propensity score adjusted $\mathrm{P}$-values. ${ }^{\mathrm{b}} \mathrm{A}$ patient with mutations in one or more of the three genes (BRAF, KRAS, PIK3CA) was counted as a mutated case in $\mathrm{PI}(3) \mathrm{K}$ signalling pathway. ${ }^{\mathrm{C}} 20 \mathrm{q}$ low amplifications are defined as amplifications smaller than the median of the mean $20 \mathrm{q}$ (cut-off $0.224 \log 2$ ) and $20 \mathrm{q}$ high vice versa.

among the three groups (Table 2). KRAS and BRAF mutations were not observed in the same tumour, which is consistent with previous observations (Figure 1) (He et al, 2009).

For further analyses, we combined the M0 with the PM group because no statistical differences were found for mutations in the $\mathrm{PI}(3) \mathrm{K}$ signalling pathway or the $20 \mathrm{q}$ status between these groups $(P=0.83$ and 0.86 , respectively). The LM group showed a trend of fewer KRAS mutations compared with the M0-PM group $(P=0.06)$ and no $B R A F$ mutations (Table 2).

In total, $62(47 \%)$ cases showed activation of the $\mathrm{PI}(3) \mathrm{K}$ signalling pathway by having mutation in at least one of the three genes (Table 2), where $50(38 \%)$ cases had mutations in a single gene and $12(9 \%)$ cases had mutations in two genes (PIK3CA and $B R A F$ or PIK3CA and KRAS). We note that two patients were missing either KRAS or BRAF data; however, they were classified as having a pathway mutation owing to harbouring a PIK3CA mutation. For nine patients, none of the mutations could be assessed $(7 \%)$. Remarkably, mutation of the $\mathrm{PI}(3) \mathrm{K}$ signalling pathway was significantly less present in the LM group compared with the combined M0-PM group $(P=0.003)$. The LM group showed $27 \%$ (13 out of 48 ) PI(3)K signalling pathway mutations, whereas this was $62 \%$ (24 out of 39 ) and $54 \%$ ( 25 out of 46 ) in the $\mathrm{M} 0$ and PM group, respectively.

CpG-island methylator phenotype CpG-island methylator phenotype status was significantly different among the three groups $(P=0.03)$ (Table 2). The LM group revealed the lowest CIMP-high rate of $4 \%$ ( 2 out of 48 ), whereas the M0 and PM groups had 18 and $30 \%$ of CIMP-high, respectively. This remained significantly different when the LM group was compared with the M0-PM

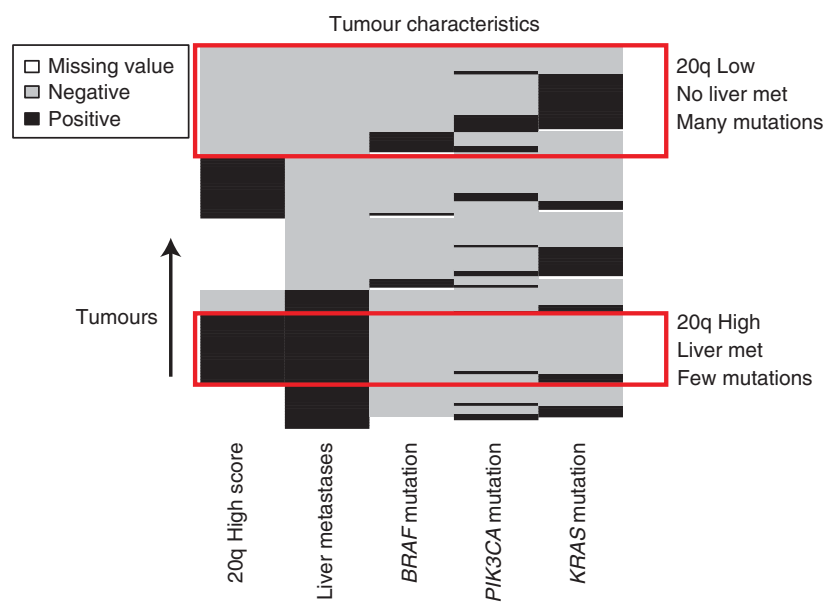

Figure I This figure shows the relation between the $20 \mathrm{q}$ gain status, liver metastasis $(L M)$ and the mutation status of BRAF, PIK3CA and KRAS. Black means the patient is positive for either 20q gain, LM or one of the mutations, whereas gray means that the patient was negative for these measurements. White values indicate that these patients were not tested for the condition. Red boxes indicate two distinct patient population, highlighting the relation between $20 \mathrm{q}$ gain, LM and the mutations.

group $(P=0.05)$. The difference between $\mathrm{M} 0$ and $\mathrm{PM}$ was not significant $(P=0.18)$. According to the literature (Samowitz et al, 2005; Ogino et al, 2006), CIMP-high is tightly associated with 
Table 3 Co-occurrence in all primary CRC of CIMP, BRAF and MSI

\begin{tabular}{lcccc}
\hline & $\begin{array}{c}\text { CIMP-low } \\
(\mathbf{n}=\mathbf{1 0 8})\end{array}$ & $\begin{array}{c}\text { CIMP-high } \\
(\mathbf{n}=\mathbf{2 3})\end{array}$ & $\begin{array}{c}\text { Total } \\
(\mathbf{n}=\mathbf{1 3} \mathbf{I})\end{array}$ & $\begin{array}{c}\text { P-value } \\
\text { Fisher's } \\
\text { exact }\end{array}$ \\
\hline BRAF & & & & \\
$\quad$ Wild type & $98(91 \%)$ & $15(65 \%)$ & $113(86 \%)$ & 0.003 \\
Mutated & $5(5 \%)$ & $6(26 \%)$ & $11(8 \%)$ & \\
Missing & $5(5 \%)$ & $2(9 \%)$ & $7(5 \%)$ & \\
MSI & & & & \\
$\quad$ Stable/low & $104(96 \%)$ & $17(74 \%)$ & $121(92 \%)$ & 0.11 \\
High & $2(2 \%)$ & $2(9 \%)$ & $4(3 \%)$ & \\
Missing & $2(2 \%)$ & $4(17 \%)$ & $6(5 \%)$ & \\
\hline
\end{tabular}

Abbreviations: $\mathrm{BRAF}=\mathrm{B}$-type Raf kinase; $\mathrm{CIMP}=\mathrm{CpG}$-island methylator phenotype; $\mathrm{CRC}=$ colorectal cancer; $\mathrm{MSI}=$ microsatellite instability .

Table 4a Co-occurrence in all primary $\mathrm{CRC}$ of $\mathrm{PI}(3) \mathrm{K}$ signalling pathway mutation and chromosomal amplification of $20 \mathrm{q}$

\begin{tabular}{lcccccc}
\hline & $\begin{array}{c}\text { 20q } \\
\text { Low }\end{array}$ & $\begin{array}{c}\text { 20q } \\
\text { High }\end{array}$ & Missing & All & $\begin{array}{c}\text { P-value } \\
\text { Fisher's exact }\end{array}$ \\
\hline No PI(3)K pathway mutation & 14 & 33 & 15 & 62 & $<0.0001$ \\
PI(3)K Pathway mutation & 31 & 11 & 20 & 62 & \\
Missing & 1 & 3 & 5 & 9 & \\
All & 46 & 47 & 40 & 133 & \\
\hline
\end{tabular}

Abbreviations: $C R C=$ colorectal cancer; $\mathrm{PI}(3) \mathrm{K}=$ phosphoinositide 3-kinase.

Table $\mathbf{4 b}$ Co-occurrence in primary $\mathrm{CRC}$ of $\mathrm{PI}(3) \mathrm{K}$ signalling pathway mutation and chromosomal amplification of $20 \mathrm{q}$ for M0+PM vs LM patients

\begin{tabular}{|c|c|c|c|c|c|}
\hline \multirow[b]{2}{*}{$20 q$} & \multirow[b]{2}{*}{$\mathrm{PI}(3) \mathrm{K}$ pathway } & \multicolumn{2}{|c|}{$M 0+P M$} & \multicolumn{2}{|c|}{ LM } \\
\hline & & $n$ & $\%$ & $n$ & $\%$ \\
\hline \multirow[t]{2}{*}{ Low } & Wild type & 9 & 15.8 & 5 & 15.6 \\
\hline & Mutated & 28 & 49.1 & 3 & 9.4 \\
\hline \multirow{2}{*}{ High } & Wild type & 13 & 22.8 & 20 & 62.5 \\
\hline & Mutated & 7 & 12.3 & 4 & 12.5 \\
\hline
\end{tabular}

Abbreviations: $C R C=$ colorectal cancer; $L M=$ liver metastasis; $\mathrm{PI}(3) \mathrm{K}=$ phosphoinositide 3-kinase; $\mathrm{PM}=$ peritoneal metastasis.

$B R A F$ mutation, which was also seen in our series $(P=0.003)$ (Table 3).

Chromosomal instability and $P I(3) K$ signalling pathway mutations Our recent study had shown that the three groups had an overall similar pattern of chromosomal aberrations. Furthermore, chromosome $20 \mathrm{q}$ was significantly more gained (20q high; above median of the mean $\log 220 \mathrm{q}$ ) in the LM group compared with the M0-PM group (KSE, $P<0.05$, Bonferroni multiple testing corrected) (Bruin et al, 2010).

Here we observed a strong inverse correlation between $20 \mathrm{q}$ amplification and $\mathrm{PI}(3) \mathrm{K}$ signalling pathway mutation $(P<0.0001)$ (Table $4 \mathrm{a}$ ). Predominantly patients who were $20 \mathrm{q}$ low showed a $\mathrm{PI}(3) \mathrm{K}$ signalling pathway mutation and vice versa (Table $4 \mathrm{a}$ and Figure 1). Table $4 \mathrm{~b}$ shows that patients who developed LM were characterised by primary CRC with a $20 \mathrm{q}$ high (amplified) $(62.5 \%)$ profile and a wild-type $\mathrm{PI}(3) \mathrm{K}$ signalling pathway, whereas the M0-PM patients by a $20 \mathrm{q}$ low $(49.1 \%)$ and a mutated PI(3)K signalling pathway (Table $4 \mathrm{~b}$ ). In the LM group, only $12.5 \%$ of the patients were $20 \mathrm{q}$ high in combination with a mutation in the $\mathrm{PI}(3) \mathrm{K}$ signalling pathway; $9.4 \%$ showed $20 \mathrm{q}$ low with a mutation in the $\mathrm{PI}(3) \mathrm{K}$ signalling pathway and $15.6 \%$ was $20 \mathrm{q}$ low with a wild-type $\mathrm{PI}(3) \mathrm{K}$ signalling pathway. The overall comparison of the distributions of $20 \mathrm{q}$ and PI(3)K between LM and M0-PM patients was significant $(P=0.0002)$.

MSI status Four out of 133 patients were identified as MSI-high, with three MSI-high patients in the M0 group and one in the PM group. No association between MSI and CIMP-high was observed (Table 3).

\section{DISCUSSION}

The current standard for early detection of CRC liver metastases is the evaluation by imaging tools including ultrasound, MRI and PET/CT (Mauchley et al, 2005; Ruers et al, 2009). Furthermore, periodic clinical assessment and laboratory tests (e.g., carcinoembryonic-antigen tests, liver-function tests and complete blood counts) are performed to monitor signs of recurrence. However, these surveillance strategies have limitations owing to the lack of sufficient sensitivity and specificity (Pfister et al, 2004).

It is generally believed that circulating tumour cells, tumourspecific DNA methylation markers, gene expression profiles and MSI profiling may indicate which CRC patients are at higher risk to develop a recurrence. In addition, chromosomal instability of specific chromosomes, for example, $18 \mathrm{q}$ or $20 \mathrm{q}$, have been associated with poor prognosis and related to liver metastases, respectively (Nanashima et al, 1997; Hidaka et al, 2000; Eschrich et al, 2005; Popat et al, 2005; Barrier et al, 2006; Cardoso et al, 2007; Lin et al, 2007; Anjomshoaa et al, 2008; Bruin et al, 2010; Kim et al, 2010; Salazar et al, 2011).

In this study of primary colorectal tumours, we aimed to evaluate the combined value of mutations in the PI(3)K signalling pathway, the CIMP, MSI and the aberration of chromosome $20 \mathrm{q}$ in primary colorectal tumours to predict the occurrence of liver metastases. We found that the primary tumours of patients who developed liver metastases are characterised not only by significantly higher amplifications of chromosome $20 \mathrm{q}(P=0.003)$, but also by significantly lower mutations in the $\mathrm{PI}(3) \mathrm{K}$ signalling pathway $(P=0.003)$ and hardly ever CIMP-high $(P=0.05)$. We revealed a strong inverse association between $20 \mathrm{q}$ amplification and mutations in the $\mathrm{PI}(3) \mathrm{K}$ pathway.

Chromosome $20 \mathrm{q}$ has previously been related to tumour progression, worse patient survival and observed in liver metastases (Aust et al, 2004; Bruin et al, 2010). Consequently, a further understanding of the candidate genes located on chromosome $20 \mathrm{q}$ amplification may guide us to understand the biological mechanisms in the development of liver metastases. Several genes located on 20q, for example, the oncogenes located on 20q13.1, such as CAS/CSE1L, NABC1, ZNF217, Aurora2 (BTAK, STK15) and the ubiquitin-conjugating enzyme E2C (UBE2C), have been described to have an important role in tumour progression and liver metastases. Interestingly, none of these genes are related to the PI(3)K signalling pathway and therefore further strengthen the conclusion that these two phenomena are mutually exclusive (Aust et al, 2004; Rooney et al, 2004; Takahashi et al, 2006).

Several molecular studies have revealed that KRAS mutation status influences sensitivity to EGFR-targeted drugs (Normanno et al, 2009). Based on these findings, the European Medicines Agency and the US Food and Drug administration have placed restrictions on the usage of EGFR-targeted drugs and only approved for CRC metastatic patients with wild-type KRAS tumours. In patients without KRAS mutation, supplementary genotyping of $B R A F, N R A S$ and PIK3CA could result in further improvement of response rates in the treatment with EGFRtargeted drugs. However, even a combination of all known 
mutations still leaves more than half of the non-responses unexplained (De Roock et al, 2010). This together with the results of our study may suggest that these patients do not depend on the $\mathrm{PI}(3) \mathrm{K}$ signalling pathway and therefore might mean that EGFRrelated therapy can be specially appropriate for patients with CRC liver metastasis.

Patients with LM selected for this study were treated with liver perfusion. These patients are characterised having multiple and/or in-operable metastases. This may influence the applicability of our conclusion for all CRC patients because it is unknown whether the biology of these patients is different from the overall group of patients who develop liver metastases. However, we have chosen this approach because these LM patients were representative for a group with high specificity for liver metastases development, that is, multiple metastases confined to the liver.

Despite the fact that patients in this study were selected and may not represent the general CRC patient population, our findings do reveal that patients at risk for developing liver metastases could be identified based on molecular characteristics of the primary tumour. Such patients should be frequently screened with modern imaging tools and are most likely to benefit from additional chemotherapy or targeted drugs. Further research needs to be carried out to validate these findings in an independent cohort of patients

Molecular changes such as the presence of $20 \mathrm{q}$ amplification combined with the absence of mutations in the PI(3) K signalling pathway and low CIMP in a CRC primary tumour might become a reason to perform tailored follow-up and eventually targeted therapy.

\section{ACKNOWLEDGEMENTS}

We thank Dr I Simon, Dr A Broeks and Dr LF Wessels for the critical reading of the manuscript.

\section{Conflict of interest}

The authors declare no conflict of interest.

\section{REFERENCES}

Andreyev HJ, Norman AR, Cunningham D, Oates JR, Clarke PA (1998) Kirsten ras mutations in patients with colorectal cancer: the multicenter 'RASCAL' study. J Natl Cancer Inst 90: 675-684

Anjomshoaa A, Lin YH, Black MA, McCall JL, Humar B, Song S, Fukuzawa R, Yoon HS, Holzmann B, Friederichs J, van Rij A, Thompson-Fawcett M, Reeve AE (2008) Reduced expression of a gene proliferation signature is associated with enhanced malignancy in colon cancer. Br J Cancer 99: $966-973$

Aust DE, Muders M, Kohler A, Schmidt M, Diebold J, Muller C, Lohrs U, Waldman FM, Baretton GB (2004) Prognostic relevance of 20q13 gains in sporadic colorectal cancers: a FISH analysis. Scand J Gastroenterol 39: $766-772$

Barault L, Veyrie N, Jooste V, Lecorre D, Chapusot C, Ferraz JM, Lievre A, Cortet M, Bouvier AM, Rat P, Roignot P, Faivre J, Laurent-Puig P, Piard F (2008) Mutations in the RAS-MAPK, PI(3)K (phosphatidylinositol-3-OH kinase) signaling network correlate with poor survival in a populationbased series of colon cancers. Int J Cancer 122: 2255-2259

Barrier A, Boelle PY, Roser F, Gregg J, Tse C, Brault D, Lacaine F, Houry S, Huguier M, Franc B, Flahault A, Lemoine A, Dudoit S (2006) Stage II colon cancer prognosis prediction by tumor gene expression profiling. $J$ Clin Oncol 24: 4685-4691

Bruin SC, Klijn C, Liefers GJ, Braaf LM, Joosse SA, van Beers EH, Verwaal VJ, Morreau H, Wessels LF, van Velthuysen ML, Tollenaar RA, 't Veer LJ (2010) Specific genomic aberrations in primary colorectal cancer are associated with liver metastases. BMC Cancer 10: 662

Cardoso J, Boer J, Morreau H, Fodde R (2007) Expression and genomic profiling of colorectal cancer. Biochim Biophys Acta 1775: 103-137

D'Agostino Jr RB (1998) Propensity score methods for bias reduction in the comparison of a treatment to a non-randomized control group. Stat Med 17: $2265-2281$

De Roock W, Claes B, Bernasconi D, De Schutter J, Biesmans B, Fountzilas G, Kalogeras KT, Kotoula V, Papamichael D, Laurent-Puig P, PenaultLlorca F, Rougier P, Vincenzi B, Santini D, Tonini G, Cappuzzo F, Frattini M, Molinari F, Saletti P, De Dosso S, Martini M, Bardelli A, Siena S, Sartore-Bianchi A, Tabernero J, Macarulla T, Di Fiore F, Gangloff AO, Ciardiello F, Pfeiffer P, Qvortrup C, Hansen TP, Van Cutsem E, Piessevaux H, Lambrechts D, Delorenzi M, Tejpar S (2010) Effects of KRAS, BRAF, NRAS, and PIK3CA mutations on the efficacy of cetuximab plus chemotherapy in chemotherapy-refractory metastatic colorectal cancer: a retrospective consortium analysis. Lancet Oncol 11: $753-762$

Eschrich S, Yang I, Bloom G, Kwong KY, Boulware D, Cantor A, Coppola D, Kruhoffer M, Aaltonen L, Orntoft TF, Quackenbush J, Yeatman TJ (2005) Molecular staging for survival prediction of colorectal cancer patients. J Clin Oncol 23: 3526-3535

Fearon ER, Vogelstein B (1990) A genetic model for colorectal tumorigenesis. Cell 61: $759-767$

Fong Y, Fortner J, Sun RL, Brennan MF, Blumgart LH (1999) Clinical score for predicting recurrence after hepatic resection for metastatic colorectal cancer: analysis of 1001 consecutive cases. Ann Surg 230: $309-318$

Galandiuk S, Wieand HS, Moertel CG, Cha SS, Fitzgibbons Jr RJ, Pemberton JH, Wolff BG (1992) Patterns of recurrence after curative resection of carcinoma of the colon and rectum. Surg Gynecol Obstet 174: 27 - 32

Gleisner AL, Choti MA, Assumpcao L, Nathan H, Schulick RD, Pawlik TM (2008) Colorectal liver metastases: recurrence and survival following hepatic resection, radiofrequency ablation, and combined resectionradiofrequency ablation. Arch Surg 143: $1204-1212$

He Y, Van't Veer LJ, Mikolajewska-Hanclich I, van Velthuysen ML, Zeestraten EC, Nagtegaal ID, van de Velde CJ, Marijnen CA (2009) PIK3CA mutations predict local recurrences in rectal cancer patients. Clin Cancer Res 15: 6956-6962

Hidaka S, Yasutake T, Takeshita H, Kondo M, Tsuji T, Nanashima A, Sawai T, Yamaguchi H, Nakagoe T, Ayabe H, Tagawa Y (2000) Differences in 20q13.2 copy number between colorectal cancers with and without liver metastasis. Clin Cancer Res 6: 2712-2717

Jass JR (2007) Classification of colorectal cancer based on correlation of clinical, morphological and molecular features. Histopathology 50: $113-130$

Jass JR, Whitehall VL, Young J, Leggett BA (2002) Emerging concepts in colorectal neoplasia. Gastroenterology 123: $862-876$

Joosse SA, van Beers EH, Nederlof PM (2007) Automated array-CGH optimized for archival formalin-fixed, paraffin-embedded tumor material. BMC Cancer 7: 43

Joosse SA, van Beers EH, Tielen IH, Horlings H, Peterse JL, Hoogerbrugge N, Ligtenberg MJ, Wessels LF, Axwijk P, Verhoef S, Hogervorst FB, Nederlof PM (2009) Prediction of BRCA1-association in hereditary nonBRCA1/2 breast carcinomas with array-CGH. Breast Cancer Res Treat 116: $479-489$

Kato S, Iida S, Higuchi T, Ishikawa T, Takagi Y, Yasuno M, Enomoto M, Uetake H, Sugihara K (2007) PIK3CA mutation is predictive of poor survival in patients with colorectal cancer. Int J Cancer 121: 1771-1778

Kets CM, van Krieken JH, van Erp PE, Feuth T, Jacobs YH, Brunner HG Ligtenberg MJ, Hoogerbrugge N (2008) Is early-onset microsatellite and chromosomally stable colorectal cancer a hallmark of a genetic susceptibility syndrome? Int J Cancer 122: 796-801

Kim MS, Lee J, Sidransky D (2010) DNA methylation markers in colorectal cancer. Cancer Metast Rev 29: $181-206$

Lengauer C, Kinzler KW, Vogelstein B (1997) Genetic instability in colorectal cancers. Nature 386: 623-627

Lin YH, Friederichs J, Black MA, Mages J, Rosenberg R, Guilford PJ, Phillips V, Thompson-Fawcett M, Kasabov N, Toro T, Merrie AE, van Rij A, Yoon HS, McCall JL, Siewert JR, Holzmann B, Reeve AE (2007) Multiple gene expression classifiers from different array platforms predict poor prognosis of colorectal cancer. Clin Cancer Res 13: 498 - 507

Marinelli A, Vahrmeijer AL, van de Velde CJ (1998) Phase I/II studies of isolated hepatic perfusion with mitomycin $\mathrm{C}$ or melphalan in patients 
with colorectal cancer hepatic metastases. Recent Results Cancer Res 147: $83-94$

Mauchley DC, Lynge DC, Langdale LA, Stelzner MG, Mock CN, Billingsley KG (2005) Clinical utility and cost-effectiveness of routine preoperative computed tomography scanning in patients with colon cancer. Am J Surg 189: $512-517$

Nanashima A, Yamaguchi H, Yasutake T, Sawai T, Kusano H, Tagawa Y, Nakagoe T, Ayabe H (1997) Gain of chromosome 20 is a frequent aberration in liver metastasis of colorectal cancers. Dig Dis Sci 42: $1388-1393$

Normanno N, Tejpar S, Morgillo F, De Luca A, Van Cutsem E, Ciardiello F (2009) Implications for KRAS status and EGFR-targeted therapies in metastatic CRC. Nat Rev Clin Oncol 6: 519-527

Nosho K, Kawasaki T, Ohnishi M, Suemoto Y, Kirkner GJ, Zepf D, Yan L, Longtine JA, Fuchs CS, Ogino S (2008) PIK3CA mutation in colorectal cancer: relationship with genetic and epigenetic alterations. Neoplasia 10: $534-541$

Nygren AO, Ameziane N, Duarte HM, Vijzelaar RN, Waisfisz Q, Hess CJ, Schouten JP, Errami A (2005) Methylation-specific MLPA (MS-MLPA): simultaneous detection of $\mathrm{CpG}$ methylation and copy number changes of up to 40 sequences. Nucleic Acids Res 33: e128

Ogino S, Cantor M, Kawasaki T, Brahmandam M, Kirkner GJ, Weisenberger DJ, Campan M, Laird PW, Loda M, Fuchs CS (2006) CpG island methylator phenotype (CIMP) of colorectal cancer is best characterised by quantitative DNA methylation analysis and prospective cohort studies. Gut 55: 1000 - 1006

Ogino S, Kawasaki T, Kirkner GJ, Kraft P, Loda M, Fuchs CS (2007) Evaluation of markers for $\mathrm{CpG}$ island methylator phenotype (CIMP) in colorectal cancer by a large population-based sample. J Mol Diagn 9: $305-314$

Ogino S, Nosho K, Kirkner GJ, Kawasaki T, Meyerhardt JA, Loda M, Giovannucci EL, Fuchs CS (2009a) CpG island methylator phenotype, microsatellite instability, BRAF mutation and clinical outcome in colon cancer. Gut 58: 90 - 96

Ogino S, Nosho K, Kirkner GJ, Shima K, Irahara N, Kure S, Chan AT, Engelman JA, Kraft P, Cantley LC, Giovannucci EL, Fuchs CS (2009b) PIK3CA mutation is associated with poor prognosis among patients with curatively resected colon cancer. J Clin Oncol 27: 1477-1484

Oikonomou E, Pintzas A (2006) Cancer genetics of sporadic colorectal cancer: BRAF and PI3KCA mutations, their impact on signaling and novel targeted therapies. Anticancer Res 26: 1077-1084

Pfister DG, Benson III AB, Somerfield MR (2004) Clinical practice. Surveillance strategies after curative treatment of colorectal cancer. $N$ Engl J Med 350: 2375 - 2382

Popat S, Hubner R, Houlston RS (2005) Systematic review of microsatellite instability and colorectal cancer prognosis. J Clin Oncol 23: 609-618

Rees M, Tekkis PP, Welsh FK, O'Rourke T, John TG (2008) Evaluation of long-term survival after hepatic resection for metastatic colorectal cancer: a multifactorial model of 929 patients. Ann Surg 247: 125-135

Rodriguez-Moranta F, Salo J, Arcusa A, Boadas J, Pinol V, Bessa X, BatisteAlentorn E, Lacy AM, Delgado S, Maurel J, Pique JM, Castells A (2006) Postoperative surveillance in patients with colorectal cancer who have undergone curative resection: a prospective, multicenter, randomized, controlled trial. J Clin Oncol 24: 386-393

Rooney PH, Boonsong A, McFadyen MC, McLeod HL, Cassidy J, Curran S, Murray GI (2004) The candidate oncogene ZNF217 is frequently amplified in colon cancer. J Pathol 204: 282-288

Ruers TJ, Wiering B, van der Sijp JR, Roumen RM, de Jong KP, Comans EF, Pruim J, Dekker HM, Krabbe PF, Oyen WJ (2009) Improved selection of patients for hepatic surgery of colorectal liver metastases with (18)F-FDG PET: a randomized study. J Nucl Med 50: 1036-1041

Sadahiro S, Suzuki T, Ishikawa K, Nakamura T, Tanaka Y, Masuda T, Mukoyama S, Yasuda S, Tajima T, Makuuchi H, Murayama C (2003) Recurrence patterns after curative resection of colorectal cancer in patients followed for a minimum of ten years. Hepatogastroenterology 50: $1362-1366$
Salazar R, Roepman P, Capella G, Moreno V, Simon I, Dreezen C, LopezDoriga A, Santos C, Marijnen C, Westerga J, Bruin S, Kerr D, Kuppen P, van de Velde C, Morreau H, Van Velthuysen L, Glas AM, Van't Veer LJ, Tollenaar R (2011) Gene expression signature to improve prognosis prediction of stage II and III colorectal cancer. J Clin Oncol 29: 17-24

Samowitz WS, Albertsen H, Herrick J, Levin TR, Sweeney C, Murtaugh MA, Wolff RK, Slattery ML (2005) Evaluation of a large, population-based sample supports a $\mathrm{CpG}$ island methylator phenotype in colon cancer. Gastroenterology 129: $837-845$

Samuels Y, Wang Z, Bardelli A, Silliman N, Ptak J, Szabo S, Yan H, Gazdar A, Powell SM, Riggins GJ, Willson JK, Markowitz S, Kinzler KW, Vogelstein B, Velculescu VE (2004) High frequency of mutations of the PIK3CA gene in human cancers. Science 304: 554

Shaw RJ, Cantley LC (2006) Ras, PI(3)K and mTOR signalling controls tumour cell growth. Nature 441: 424-430

Takahashi Y, Ishii Y, Nishida Y, Ikarashi M, Nagata T, Nakamura T, Yamamori S, Asai S (2006) Detection of aberrations of ubiquitinconjugating enzyme E2C gene (UBE2C) in advanced colon cancer with liver metastases by DNA microarray and two-color FISH. Cancer Genet Cytogenet 168: $30-35$

Thiagalingam S, Laken S, Willson JK, Markowitz SD, Kinzler KW, Vogelstein B, Lengauer C (2001) Mechanisms underlying losses of heterozygosity in human colorectal cancers. Proc Natl Acad Sci USA 98: $2698-2702$

van Iersel LB, Gelderblom H, Vahrmeijer AL, van Persijn van Meerten EL, Tijl FG, Putter H, Hartgrink HH, Kuppen PJ, Nortier JW, Tollenaar RA, van de Velde CJ (2008) Isolated hepatic melphalan perfusion of colorectal liver metastases: outcome and prognostic factors in 154 patients. Ann Oncol 19: 1127-1134

Velho S, Oliveira C, Ferreira A, Ferreira AC, Suriano G, Schwartz Jr S, Duval A, Carneiro F, Machado JC, Hamelin R, Seruca R (2005) The prevalence of PIK3CA mutations in gastric and colon cancer. Eur $J$ Cancer 41: $1649-1654$

Verwaal VJ, Bruin S, Boot H, van Slooten G, van Tinteren H (2008) 8-year follow-up of randomized trial: cytoreduction and hyperthermic intraperitoneal chemotherapy $v s$ systemic chemotherapy in patients with peritoneal carcinomatosis of colorectal cancer. Ann Surg Oncol 15: $2426-2432$

Verwaal VJ, van Ruth S, de Bree E, van Sloothen GW, van Tinteren H, Boot H, Zoetmulder FA (2003) Randomized trial of cytoreduction and hyperthermic intraperitoneal chemotherapy $v s$ systemic chemotherapy and palliative surgery in patients with peritoneal carcinomatosis of colorectal cancer. J Clin Oncol 21: 3737-3743

Vivanco I, Sawyers CL (2002) The phosphatidylinositol 3-kinase AKT pathway in human cancer. Nat Rev Cancer 2: 489-501

Vogelstein B, Fearon ER, Hamilton SR, Kern SE, Preisinger AC, Leppert M, Nakamura Y, White R, Smits AM, Bos JL (1988) Genetic alterations during colorectal-tumor development. $N$ Engl J Med 319: 525-532

Weisenberger DJ, Siegmund KD, Campan M, Young J, Long TI, Faasse MA, Kang GH, Widschwendter M, Weener D, Buchanan D, Koh H, Simms L, Barker M, Leggett B, Levine J, Kim M, French AJ, Thibodeau SN, Jass J, Haile R, Laird PW (2006) CpG island methylator phenotype underlies sporadic microsatellite instability and is tightly associated with BRAF mutation in colorectal cancer. Nat Genet 38: 787-793

Weiss L, Grundmann E, Torhorst J, Hartveit F, Moberg I, Eder M, FenoglioPreiser CM, Napier J, Horne CH, Lopez MJ (1986) Haematogenous metastatic patterns in colonic carcinoma: an analysis of 1541 necropsies. J Pathol 150: 195-203

Weitz J, Koch M, Debus J, Hohler T, Galle PR, Buchler MW (2005) Colorectal cancer. Lancet 365: 153-165

Welch JP, Donaldson GA (1979) The clinical correlation of an autopsy study of recurrent colorectal cancer. Ann Surg 189: 496-502

Yuen ST, Davies H, Chan TL, Ho JW, Bignell GR, Cox C, Stephens P, Edkins S, Tsui WW, Chan AS, Futreal PA, Stratton MR, Wooster R, Leung SY (2002) Similarity of the phenotypic patterns associated with BRAF and KRAS mutations in colorectal neoplasia. Cancer Res 62: 6451-6455 